\title{
La evaluación económica en salud
}

"...Estamos en una situación afortunada, aunque dolorosa de tener a nuestra disposición más actividades beneficiosas de las que podemos financiar... la decisión explícita de asignar recursos a un paciente es inevitablemente una decisión implícita de negárselos a otro paciente".

Alan Williams, 1988

Alan Williams, un connotado economista británico graficaba así, lo que en economía de la salud constituye "el costo de oportunidad". En el campo de la economía de la salud, y especialmente en el sector público, el costo de oportunidad, implica el análisis de la distribución de recursos (normalmente escasos) entre necesidades de cuidados de salud que son múltiples y crecientes.

Tanto la Economía de la Salud como la Evaluación Económica de Intervenciones de salud (esta última una subdisciplina de la primera), son disciplinas bastante jóvenes que han alcanzado un gran desarrollo conceptual y metodológico en países desarrollados, principalmente en el Reino Unido y Estados Unidos. La aplicación práctica de la Evaluación Económica en salud ha llegado a formalizarse en la creación de agencias que persiguen la "Evaluación de Tecnologías Sanitarias" al momento de tomar decisiones sobre que intervenciones de salud, tecnologías y/o medicamentos garantizar, proveer y/o reembolsar. Países como Australia, Canadá, Inglaterra, Alemania y Suecia entre otros, cuentan con estas organizaciones donde las evaluaciones económicas forman parte de un trámite obligatorio, ya sea dentro del servicio público, como en el contexto de reembolso de medicamentos por parte de los seguros de salud.

Con justa razón, muchos han argumentado que si la Economía de la Salud se ha hecho tema relevante en países de altos ingresos y recursos, ésta debiera ser aún más útil en países en desarrollo. En Chile, este tema no es en lo absoluto desconocido, y con frecuencia escuchamos hablar o argumentar sobre "la costo efectividad" de tal o cual intervención y/o procedimiento. Sin embargo, las tecnicidades del tema van más allá de lo que uno puede intuir en una primera instancia y la mayor parte de las fuentes bibliográficas donde se discuten y se proveen los lineamientos metodológicos están aún en idioma inglés.

La idea de esta serie se remonta ya a un par de años atrás, en la búsqueda por contribuir a divulgar la Evaluación Económica de intervenciones de salud entre los profesionales chilenos, tanto del área técnica como en la toma de decisión en salud.

Para llevar a cabo este proyecto, se decidió convocar a investigadores principalmente chilenos de diferentes universidades del país con un reconocido interés en el área. Los autores de los distintos artículos son en algunos casos connotados actores de la salud pública que han incursionado en el tema de la economía de la salud y en otras ocasiones, investigadores relativamente jóvenes que buscan desarrollarse en esta área. Algunos han tenido la posibilidad de conducir o ser contraparte en estudios de costo efectividad en terreno. En la autoría de los documentos se logra además un equilibrio entre la participación de Economistas de las Salud ( 3 artículos) y clínicos con formación y/o profundo interés en esta área (4 artículos).

La presente serie no representa en lo absoluto una revisión exhaustiva del tema de las evaluaciones económicas, ni pretende formar profesionales en esta área. Su objetivo principal es servir como introducción a un tema que se hace cada vez relevante en el área de la salud.

Sin más, teniendo muy claro que los resultados de la salud en función de los costos son sólo un aspecto de la toma de decisiones, esperamos que esta serie resulte no sólo interesante por su contribución metodológica, sino que sea además una oportunidad de inspiración y reflexión sobre los criterios que priman al momento de priorizar programas e intervenciones de salud en nuestro país.

Palabras clave: Determinación de prioridades, economía de la salud, evaluación económica.

Marianela Castillo-Riquelme Economista en Salud

Víctor Zarate

Especialista en Salud Pública 